\title{
The Reflection of the Diversification of Training Mode about Talents of Automation Major
}

\author{
Zhang Lanyong, Liu Sheng ${ }^{1}$
}

\begin{abstract}
(College of Automation, Harbin Engineer Abstract-This paper analyzes the main drawbacks of training mode about talents of Control Science and Engineering, and points out the urgency about bringing up high-quality talents, especially top-notch innovative talents in our country. It also raises the reflection of the diversification of training mode about high-quality talents of Control Science and Engineering.
\end{abstract}

Keywords-Automation Major; Training Mode; High-Quality Talents; Higher School

\section{PREFACE}

Because China's socialist construction has entered a new stage of development, the reform of education in colleges and universities is still far from meeting the requirements of China's economic, technological and social development. So there are some disadvantages, especially the traditional training models are relatively single, professional and knowledge is relatively narrow, teaching content is relatively old, practical aspects are weak and the education system is not flexible enough, and so on. University as a whole has not been able to form a good-quality environment beneficial to bring up high-quality specialized talents, especially top-notch innovative talents. Therefore, strengthening the various types of high-quality specialized talent, especially top-notch innovative talents' cultivation is not only an important task of colleges and universities under the new situation, but also is a new demand to the reform of colleges and universities. In this paper, the reflection of the diversification of training mode about high-quality talents of Control Science and Engineering is raised.

\section{THE MAIN DRAWBACKS OF TALENT TRAINING MODE}

$$
\text { NOW }
$$

\section{A. Theory with the Engineering Practice is not Enough}

In today's automation field, all kinds of intelligent instruments, sensors, actuators change quickly and new control modes and control strategies continue to emerge. How to keep pace with the development of automation, renewal theory of teaching content, guide the engineering practice with practice have been urgent problems to need to be solved.

\section{B. Teaching Mis Obsolete}

Nowadays, information technology changes rapidly, new theories, new methods and new technologies continue to emerge. If according to the rhythm of traditional teaching and teaching mode, it is difficult to make students to master a lot of useful new knowledge and new technologies in the limited time, and it cannot achieve the purpose of broadening the professional caliber.

\section{Bilingual Teaching}

Currently, the number of bilingual teaching courses and teachers is very small. With the increase of number of master and doctor in teacher's team, the issue of increasing exchanges of personnel can be expected to be solved in the short term. This is the main drawbacks of the current training model, the drawbacks of education become a serious impediment to bring up various high-quality specialized talents, especially top-notch innovative talents' cultivation of our culture. It must need to make us ponder deeply.

\section{IT IS URGENT TO BRING UP VARIOUS HIGH-QUALITY}

\section{SPECIALIZED TALENTS,ESPECIALLY TOP-NOTCH}

\section{INNOVATIVE TALENTS.}

In the 21st century, the great progress which human achieved in the field of knowledge and technology shows that scientific advances, technological change and innovation is the key to increase wealth, improve competitive advantage and quality of life. However, in the process of accelerating scientific and technological development, the most important factor is the role of human creativity. It is the key to master the advanced scientific technology and innovation capability. It can be seen that economic competition and competition of comprehensive national strength in today's world are gradually evolved into the competition of national quality and talents. And to a certain extent, the focus of a new round of international competition concentrated on the rich scientific, technical competence and talents of high cultural quality. Making efforts to bring up high-quality specialized talent, especially top-notch innovative talents has become an important way to achieve economic and technological development and enhance the comprehensive national strength in today's world. In today's world when technological advances improve rapidly, economic globalization develops deeply and competition of comprehensive national strength becomes increasingly fierce, who have more high-quality specialized talent, especially top-notch innovative talents, who will dominate the commanding heights of technology and economy of the world in the 21 st century, who will be able to get the initiative in the competition and win the future.

In the first 20 years of this century, concentrating our efforts on building a well-off society of a higher level is the goal of our party and our country in the new century.

\footnotetext{
${ }^{1}$ Zhang Lanyong(1983-), male, Ph.D, lecture and director of the laboratory. He is mainly engaged in the related research in the field
} of control science and engineering. Email:zlyalf@sina.com 
To achieve this goal, the key is talent, especially high-quality talent. If we only improve the national quality, but we can't bring up a large number of leaders who are able to master the world's most advanced core technologies and independent intellectual property rights and are capable of world's leading position in some fields and senior management talents who adapt to the fierce competition of the world, then, it is very difficult to enhance national creativity, promote China's economic development by leaps and bounds and bring about a great rejuvenation of the Chinese nation.

High-quality specialized talent, especially top-notch innovative talents mean these people who are leaders and outstanding talents capable of a strong sense of professionalism, sense of social responsibility, innovative spirit and ability to make a significant contribution to national development in various fields, especially science, technology and management. Whether our country can bring up a large number of high-quality specialized talent, especially top-notch innovative talents, is the key factor to achieve leapfrog development of socialist construction and narrow the gap between the developed countries and our country in economic, science and technology, and is an important strategic task for China's reform and development of higher education.

Since the founding of New China, especially the reform and opening up, our country has made tremendous historic development of education. However, since the foundation of the development of technology and education is still relatively weak, there is a great gap between the developed countries and our country in the aspect of bring up talents, especially the serious lack of high-qualified specialists and top-notch innovative talents. It has become an important constraint

To catch up with the developed countries of the world in the aspect of technological and economic development for our country. Among more than 700 million employees of our country, and the high-level specialized talent is in the most scarce position. In 2000, among 29 professional technical series, the number of people who have a title above vice senior is 1.573 million, accounting for only $5.5 \%$ of the total. For example, in the field of natural sciences and engineering sciences, in 2000, the number of scientists and engineers engaged in research and development per 10 thousand people, the United States is 41, Japan 50, Korea 21, while China is 5 , only accounting for 1/8 of American total,1/10 of Japanese total and South Korea's fourth. It shows the serious deficiencies of talents in this aspect, and there are also many new problems in terms of quality. This is a key factor why there is a great gap between the developed countries and our country in aspects of international scientific and technological competitiveness, quantity and quality of high level of research.

It is an urgent task to bring up a large number of high-quality specialized talent, especially top-notch innovative talents in the new era of educational development. It also will open up a wider space for the development and reform of education and put forward new and higher requirements. This new leap in the development process of education will further promote revolutionary changes of our country's educational content, teaching methods and other aspects of personnel training mode in the 21 st century and it is imperative.

\section{THE REFLECTION OF THE DIVERSIFICATION OF}

\section{TRAINING MODE ABOUT HIGH-QUALITY TALENTS OF}

\section{CONTROL SCIENCE AND ENGINEERING}

The subject is always facing the maritime traffic, coastal development and marine development, bringing up talents both for the Navy and national defense industry. It also makes a contribution for the Navy in the future high-tech warfare and ship-building industry. Meantime, it provides new theories and new technologies for information subject areas required by national economic and social development. The subject is basically research-oriented disciplines, has significant industry-specific and high technical level, and it has a strong scientific research team and some leaders. It enjoys a higher status in the domestic shipbuilding industry. In training talents, the formation of education system of doctorate, master's and bachelor level of degree and non-degree, training a large number of outstanding engineering and technical talents in the field of automation and having strong features of ship sea are able to provide strong support for school's "three sea a nuclear" school characteristics.

However, when it is compared with the similar subject in our country, there is a big gap between this subject and others in terms of high-level research output, high-level teachers, bringing up creative talents, etc.

The unitary training mode of enslaved education which is formed under our country' long-term autocracy is not beneficial to the current educational content, teaching methods and training model of talents and it need urgently a revolutionary reform to accelerate the pace of bringing up high-quality talents of this subject whom our educational market needs urgently, especially top-notch innovative talents. And it can catch up with the advanced world and shorten the gap. So these follow advices are necessary:

\section{A. $\quad$ correct guiding ideology}

Facing modernization, facing the world, facing the future, it is important to bring up senior specialized compound talents with the ability of solid basic knowledge, wide professional horizons, strong engineering capabilities, engineering, science, culture, business integrate each other and high comprehensive quality, innovative spirit and practical ability and so on. Follow the guiding ideology "enhanced sense of quality education, reform personnel training mode" and "knowledge, ability, quality develop coordinately," and develop practical teaching training programs. The core of reform training model lies in strengthening the quality of education, encouraging personality development, cultivating the spirit of innovation. Its core should highlight the main line, regarding developing ability as a main line; two gravity, that is to say, teaching gravity of first and second grade should focus on students' ability of thinking and learning, teaching gravity of third and fourth grade should focus on students' ability of engineering and innovation. 


\section{B. Figure Out Training Objectives}

Our country needs to bring up composite application-oriented and research-based senior technical talents who are capable of adapting to the 21 st century technology development of our country's modernization, understanding control and electrical. It requires a solid basic knowledge of control theory. Meantime, we should pay more attention to the actual production, ability and overall quality of training practice; and the creative and practical ability of using microelectronics technology, computer technology and modern control theory to transform and produce equipment.

\section{Develop Measures to Achieve the Goal of Bringing up High-Qualified Talents}

To cultivate creative talent, the key is to change teaching concepts, reform the teaching methods, teaching measurements and a single classroom training mode. The most important thing is to pay attention to the dominant position of students in the learning activities, completely change the traditional injection, cramming teaching methods, use actively heuristic discussion teaching methods; transfer "examination" education what singly imparts knowledge into "quality" education what improves creative practice ability; transfer single classroom teaching into diversity training mode.

Physical Teaching. We should move the scientific equipment and components into the classroom, and it can make teaching more intuitive and visualize.

Scene Teaching. We should move the classroom into research scene and practice facility to carry out real practical projects and production technology teaching.

Strengthen the experimental teaching, strengthen practical aspects, training engineering capabilities. Under the conditions of inadequate laboratory equipment, we can take advantage of research equipment, and guide students to do it themselves, develop innovation experiment, and stimulate students' interest and curiosity, develop rigorous and realistic style; make full use of the engineering experiment center of school's new engineering experiment center to open new experiment and develop their ability of innovation; enhance extracurricular guidance, open existing laboratory, and leave enough time and space for students' self-learning and independent thinking so that it can turn extracurricular and curricular teaching activities into an organic whole. It is helpful to conduct their personality development.

Make full use of practical teaching link like curriculum design, production practice, and graduation design, linking theory with practice, integrate study and application, develop students' practical ability of utilizing the knowledge to analyze problems and solve the problem.

Form educational teams, create educational environment, strengthening the cultural quality of education, improving the overall quality of students. Construct student work networks used to guide student to be a talent; form a student work team made up of high-level, high educational young teachers; connect professional theory with practice teaching in multiply aspect and multiply levels; set and organize various events home and abroad, culture and the arts, humanities and social sciences course, set plans to carry out reading activities and so on; develop student organizations, enrich and improve the connotation of the traditional school "three festival"; organize and carry out various special investigations, social practice and social welfare activities, combine financial classroom teaching and extra-curricular activities, combine education and teaching, combine teaching and educating people, make efforts to the cultivation of personality spiritual and moral, achieve the goal that it educates students wholly. Reorganize knowledge structure, create academic atmosphere, expand talent space, encourage personality development, improve quality of teaching.

By inviting academic leaders and academic experts and professors in various fields to regularly hold academic lectures, setting plans to carry out scientific and technological books reading activities and organizing theme proposition competitions, we can encourage and guide students to make full use of the advantages of the scientific research institutes of the chamber college to carry out science and technology interest group activities and business practices and expand the talent space and encourage individual development.

\section{CONCLUSION}

The reform project of higher education in the New Century is a large-scale systems engineering with far-reaching impact. It needs to carry out a lot of research more than what we point out, and there are a lot of work to need to be researched further by us.

\section{ACKNOWLEDGEMENT}

The work was financed by Control Science and Engineering's Exploration and Practice (2011-16) in Heilongjiang Province, Exploration and Practice in University Teachers' Research and Achievement into Innovative Personnel Training's Practice Mechanism (JG2013010202) and Harbin Engineering University undergraduate education reform project Undergraduates' Technology Innovation and Small Business System's Research and Practice (JG2014BYB13). Planning Subject of Education Department of Heilongjiang Province (GBC1213103).

\section{REFERENCE}

[1] Sun Guangyou. The development of innovative thinking ability and high-quality talents [J] Harbin College periodical, 2012, 33 (6): 11-13

[2] Liu Huadong. Developing high-quality talents is the top priority in universities [J] China Higher Education Research, 2012, 7: 69-71

[3] Yang Xuejun, Wang Jianwei. Bring up high-quality talents, gain high-level achievement [P] People's Daily, 2012, 8 (17):1-4

[4] Yang Chao, Zhang Xinyin,He Sipeng etc. Base on Harbin College periodical, use scientific research to promote teaching, build high-level application-oriented colleges [J] China Electric Power Education, 2012, 1: 4-5

[5] Zhang Yun.Analysis training talents mode that how to bring up high-quality innovative talents by combining engineering with teaching[J] Innovation and Entrepreneurship Education,2012,3(1): 23-26

[6] Li Hongtao,Xue Qinglin, Dong Jianzhen etc. Cultivate high-quality talents by teaching, research and management $[\mathrm{J}]$ Journal of Agricultural University of Hebei (Agriculture and Forestry Education Edition) 2012, 14 (5): 72-76 